\title{
Strategies for the crystallization of viruses: Using phase diagrams and gels to produce 3D crystals of Grapevine fanleaf virus
}

\author{
Pascale Schellenberger ${ }^{\mathrm{a}, \mathrm{b}}$, Gérard Demangeat ${ }^{\mathrm{a}}$, Olivier Lemaire ${ }^{\mathrm{a}}$, Christophe Ritzenthaler ${ }^{\mathrm{b}}$, \\ Marc Bergdoll ${ }^{\mathrm{b}}$, Vincent Oliéric $^{\mathrm{c}}$, Claude Sauter ${ }^{\mathrm{d}}$, Bernard Lorber ${ }^{\mathrm{d}, *}$ \\ a Institut National de la Recherche Agronomique, UMR 1131 Santé de la Vigne et Qualité du Vin, INRA/UDS, Laboratoire de Virologie et Vection, 28 rue de Herrlisheim, F-68021 \\ Colmar, France \\ ${ }^{\mathrm{b}}$ Institut de Biologie Moléculaire des Plantes (IBMP), CNRS université de Strasbourg, UPR2357, 12 rue du Général Zimmer, F-67084 Strasbourg, France \\ ${ }^{\mathrm{c}}$ Swiss Light Source, Paul Scherrer Institute, Villigen $\mathrm{CH}-5232$, Switzerland \\ ${ }^{\mathrm{d}}$ Architecture et Réactivité de l'ARN, Université de Strasbourg, CNRS, Institut de Biologie Moléculaire et Cellulaire (IBMC), 15 rue René Descartes, F-67084 Strasbourg, France
}

\section{A R T I C L E I N F O}

\section{Article history:}

Received 23 November 2010

Received in revised form 2 February 2011

Accepted 17 February 2011

Available online 23 February 2011

\section{Keywords:}

Virus

Grapevine fanleaf virus

Crystallization

Phase diagram

Agarose

Gel

Solubility

\begin{abstract}
A B S T R A C T
The small icosahedral plant RNA nepovirus Grapevine fanleaf virus (GFLV) is specifically transmitted by a nematode and causes major damage to vineyards worldwide. To elucidate the molecular mechanisms underlying the recognition between the surface of its protein capsid and cellular components of its vector, host and viral proteins synthesized upon infection, the wild type GFLV strain F13 and a natural mutant (GFLV-TD) carrying a Gly ${ }_{297}$ Asp mutation were purified, characterized and crystallized. Subsequently, the geometry and volume of their crystals was optimized by establishing phase diagrams. GFLV-TD was twice as soluble as the parent virus in the crystallization solution and its crystals diffracted X-rays to a resolution of $2.7 \AA$. The diffraction limit of GFLV-F13 crystals was extended from 5.5 to $3 \AA$ by growth in agarose gel. Preliminary crystallographic analyses indicate that both types of crystals are suitable for structure determination. Keys for the successful production of GFLV crystals include the rigorous quality control of virus preparations, crystal quality improvement using phase diagrams, and crystal lattice reinforcement by growth in agarose gel. These strategies are applicable to the production of well-diffracting crystals of other viruses and macromolecular assemblies.
\end{abstract}

(c) 2011 Elsevier Inc. All rights reserved.

\section{Introduction}

The preparation of crystals with minimal defect and excellent diffraction properties is the very first challenge of any structural biology project based on crystallography. On the one hand, the preparation of a sufficient amount of soluble, pure and homogenous material is a frequent obstacle to crystallization (see e.g. Ducruix and Giegé, 1999; McPherson, 1999). On the other hand, it may be necessary to enhance the quality of the initial crystals using crystallogenesis approaches based either on phase diagrams (see e.g. Lorber and Witz, 2008) or on crystallization in diffusive environments, like gels (reviewed in Lorber et al. (2009)) or microfluidic channels (as applied in Sauter et al. (2007)). Further, in the case of crystals of biological particles having very large unit cells, the data collection procedure must be optimized to compensate for the weak diffraction intensity and very low resolution (see e.g. Gan and Johnson, 2008; Girard et al., 2005).

\footnotetext{
* Corresponding author. Present address: The Division of Structural Biology, The Welcome Trust Center for Human Genetics, University of Oxford, Roosevelt Drive, Oxford OX3 7BN, UK.

E-mail address: b.lorber@ibmc-cnrs.unistra.fr (B. Lorber).
}

We chose to determine the crystal structure of the virus responsible for fanleaf degeneration, the most severe viral disease of grapevines worldwide. Grapevine fanleaf virus (GFLV) reduces plant vigor, crop yield by as much as $80 \%$, fruit quality, and the lifespan of vineyards by causing plant mortality (Andret-Link et al., 2004). Within the Secoviridae family, GFLV belongs to the genus Nepovirus (Sanfaçon, 2008). It is specifically transmitted from grapevine to grapevine by the soilborne nematode Xiphinema index. The icosahedral and non-enveloped GFLV virion has a diameter of about $30 \mathrm{~nm}$. Its capsid is composed of 60 identical subunits each encompassing 504 amino acid residues ( $M_{\mathrm{w}} 56 \mathrm{kDa}$, theor. $\mathrm{pI}$ 6.2). GFLV carries a positive sense bipartite RNA genome. RNA-1 and RNA-2 are encapsidated separately (Quacquarelli et al., 1976). Each is covalently attached to the virus-genome-linked protein (VPg) at its 5'terminus (Pinck et al., 1991) and has a 3' polyadenylated terminus. GFLV shares a great similarity with Tobacco Ringspot Virus (TRSV) whose structure is known (Chandrasekar and Johnson, 1998). The 515 amino acids of the polypeptide chain of the latter share $24 \%$ identity. It is arranged in a capsid with the same $T=1$ (pseudo $T=3$ ) triangulation number but TRSV is only transmitted by the nematode species Xiphinema americanum and the determinants for this specificity are not known. Obviously, 
the three-dimensional structure of the GFLV virion would give clues about its architecture and how it distinguishes from other nepoviruses. Finally, the comparison of the 3D structures of a transmissible viral particle with that of a poorly transmitted one (see below) would inform about the molecular details involved in the recognition of the surface of the capsid by cellular components of its vector and of its host or other proteins from the virus that are synthesized as soon as the host is infected.

Here we report on the strategies and experimental steps that were crucial for the production of well-diffracting GFLV crystals as well as for the collection of first diffraction datasets using synchrotron radiation. The GFLV strain F13 (GFLV-F13) derived from infectious transcripts (Viry et al., 1993) and a naturally occurring variant which differs by a single amino acid substitution in the capsid protein (GFLV-TD) were crystallized. We show how the rigorous control of the quality of every virus preparations, the improvement of crystal quality using small phase diagrams, and the enhancement of crystal stability by growth in agarose gel have led to the successful production of well-diffracting crystals. The strategies implemented for GFLV can be adapted for the crystallization and the crystallographic analysis of other viruses.

\section{Materials and methods}

\subsection{Chemicals and biochemicals}

Ammonium molybdate was purchased from Merck, molecular weight marker proteins from Sigma (Cat. No. P-1677), bentonit from Alfa Aesar, and PEG-20000 from Prolabo. Polyethylene glycol (PEG-3350), INDEX ${ }^{\mathrm{TM}}$ sparse matrix and Aqua Sil ${ }^{\mathrm{TM}}$ were from Hampton Research (Aliso Viejo, CA). Low-gelling temperature $\left(T_{\mathrm{g}}=28^{\circ} \mathrm{C}\right)$ agarose was a gift from So.bi.gel. (Hendaye, France). All solvents in contact with the virus during crystallization assays were prepared with sterile thrice-distilled water.

\subsection{Virus strain and propagation}

The GFLV F13 strain used here originated from Chenopodium quinoa plants infected with synthetic virus produced from cDNA clone of GFLV strain F13 (Vuittenez et al., 1964). After several years of mechanical inoculation in this systemic host, it produced a variant during this study. Its capsid protein gene was characterized by IC/RT/PCR and sequenced as described (Schellenberger et al., 2010) and the variant was subsequently named GFLV-TD.

\subsection{Virus purification}

Viral particles were purified essentially as described (Pinck et al., 1988) with one additional separation step on sucrose gradients. Plants were infected using crude sap from infected $C$. quinoa leaves as inoculum. At day 14 post-infection $1 \mathrm{~kg}$ of fresh infected leaves was harvested and ground at room temperature with 2 volumes of grinding buffer ( $65 \mathrm{mM}$ sodium phosphate buffer, $\mathrm{pH} 7.2$, $10 \mathrm{mM}$ EDTA, $100 \mathrm{mM}$ ascorbic acid). The crude homogenate filtered over cloth was clarified by low speed centrifugation (15 min, $1900 \mathrm{~g}, 15^{\circ} \mathrm{C}$ ) after 15 min contact with $8 \%(\mathrm{~m} / \mathrm{v})$ bentonite. The virus was then precipitated by adding $10 \%$ (m/v) PEG20000 and $1 \%(\mathrm{~m} / \mathrm{v})$ sodium chloride at room temperature. The precipitate was centrifuged at low speed centrifugation $(10,000 \mathrm{~g}$, $0.5 \mathrm{~h}, 5^{\circ} \mathrm{C}$ ) and resuspended in $5 \mathrm{mM}$ sodium phosphate buffer, $\mathrm{pH} 7.0$, and $1 \mathrm{mM}$ EDTA. After sedimentation by ultracentrifugation at $140,000 \mathrm{~g}$ for $2 \mathrm{~h}$ in $50.2 \mathrm{Ti}$ rotor (Beckman), the virus pellets were resuspended in $5 \mathrm{mM}$ sodium phosphate buffer, $\mathrm{pH}$ 7. Contaminating proteins were removed by centrifugation on a $20 \mathrm{ml}$ sucrose cushion in $5 \mathrm{mM}$ Na phosphate buffer, pH 7.0 (140,000 g,
$5 \mathrm{~h}, 50.2 \mathrm{Ti}$ rotor, Beckman). The resulting pellet was suspended in $15 \mathrm{mM}$ sodium phosphate and $5 \mathrm{mM}$ potassium phosphate, $\mathrm{pH}$ 7.0 and insoluble material removed by low speed centrifugation ( $4000 \mathrm{~g}, 10 \mathrm{~min}, 5^{\circ} \mathrm{C}$ ). The viral particles in the supernatant were then purified by two consecutive sucrose density gradient fractionations. A first gradient was established by thawing a frozen $30 \%$ $(\mathrm{m} / \mathrm{v})$ sucrose solution followed by $5 \mathrm{~h}$ centrifugation at 113,000 $g$ in a SW28 rotor (Beckmann). Its virus-containing fractions were pooled and centrifuged at $290,000 \mathrm{~g}$ for $2 \mathrm{~h}$ in 50.2Ti rotor (Beckmann). Pure virions were suspended in $15 \mathrm{mM}$ sodium phosphate and $5 \mathrm{mM}$ potassium phosphate, $\mathrm{pH} 7.0$, ultracentrifugated for $2.5 \mathrm{~h}$ through a second $60-10 \%(\mathrm{~m} / \mathrm{v})$ sucrose gradient at 210,000 $\mathrm{g}$ in SW41 rotor (Beckman), and collected with a peristaltic pump. Finally, they were resuspended in sterile water and filtered through a $0.22 \mu \mathrm{m}$ pore-size Ultrafree-MC ${ }^{\mathrm{TM}}$ membrane (Millex) prior to storage at $4{ }^{\circ} \mathrm{C}$. Routinely $1 \mathrm{mg}$ pure GFLV was obtained from $1 \mathrm{~kg}$ fresh Chenopodium leaves.

\subsection{Characterization of GFLV preparations}

The UV-absorbance of virus was measured on $2 \mu$ l solution with a Nanodrop ${ }^{\circledR}$ ND-100 spectrophotometer. The protein content of virus preparations was separated by electrophoresis (SDS-PAGE) on $10 \%(\mathrm{~m} / \mathrm{v})$ polyacrylamide gels after denaturation at $95{ }^{\circ} \mathrm{C}$ in presence of sodium dodecyl sulfate and mercaptoethanol.

Virus samples were analyzed by dynamic light scattering to verify the absence of aggregates and estimate mean particle diameter and polydispersity. Standard deviations on the diameter below $15 \%$ reflected narrow particle size distributions. Analyses were performed using a Zetasizer NanoS (Malvern Instruments, Malvern, UK). Virus solutions at $0.05 \mathrm{mg} / \mathrm{ml}$ in $0.15 \mathrm{M} \mathrm{NaCl}$ were transferred in quartz cells. Scattered intensities were recorded at $20^{\circ} \mathrm{C}$ and data processed with the DTS software developed by the manufacturer. Experimental data were corrected for solvent viscosity and refractive index.

Electron microscopy analyses were performed with a Hitachi H600 electron microscope equipped with a Hamamatsu CCD Advantage HR camera. Virus suspension ( $3 \mu \mathrm{l}$ at $0.1 \mathrm{mg} / \mathrm{ml}$ ) in water was deposited on a nickel grid coated with a polyvinyl formal (Formvar $\left.^{\circledR}\right)$ film. The excess was blotted after 2 min and then $5 \mu \mathrm{lammo-}$ nium molybdate solution at $1 \%(\mathrm{~m} / \mathrm{v})$ was added. The excess of stain was blotted after $5 \mathrm{~s}$ by contact with a piece of filter paper and the grid was air-dried at ambient temperature. Grids were examined under a potential difference of $75 \mathrm{kV}$.

\subsection{Crystallization in solution and in gel}

The initial search of crystallization conditions was done in 96well Crystalquick ${ }^{\circledR}$ LBR microplates (Greiner BioOne) with 3 round wells per reservoir using the Mosquito ${ }^{\mathrm{TM}}$ pipeting station (TTP Labtech, UK). Nanodrops were prepared by mixing $150 \mathrm{nl}$ virus at $8 \mathrm{mg} / \mathrm{ml}$ in $50 \mathrm{mM}$ Hepes, pH 7.5 with $150 \mathrm{nl}$ reservoir INDEX ${ }^{\mathrm{TM}}$ sparse matrix solution (Hampton Research) and equilibrated by vapor diffusion over $50 \mu \mathrm{l}$ reservoirs (Ducruix and Giegé, 1999, Sauter et al., in press). After 4 weeks, crystals were found in two solutions. Subsequently, series of $1 \mu \mathrm{l}$ sitting drops were prepared manually in Crystalquick ${ }^{\mathrm{TM}}$ low-profile microplates (Greiner BioOne) and equilibrated against $50 \mu$ reservoirs. A set of 16 drops covered 4 virus concentrations and 4 crystallant concentrations.

Agarose with a gelling temperature $\left(T_{\mathrm{g}}=28^{\circ} \mathrm{C}\right)$ was dissolved in distilled water at $2 \%(\mathrm{~m} / \mathrm{v})$ at $100{ }^{\circ} \mathrm{C}$. The warm solution was transferred in a syringe, filtered through a $0.45 \mathrm{~mm}^{\text {Millex }}{ }^{\mathrm{TM}}$ membrane, and dispensed in $1 \mathrm{ml}$ vials. This stock solution formed a gel at room temperature. Before use it was liquefied at $90^{\circ} \mathrm{C}$ in a heating block and kept at $35^{\circ} \mathrm{C}$. The appropriate volume of warm agarose solution was added to the mixture of virus and crystallant to reach 
a final polysaccharide concentration of $0.2 \%(\mathrm{~m} / \mathrm{v})$ (For more details, see Lorber et al., 2009). The resulting medium is viscoelastic and allows an easy harvesting of the crystals (see below). Crystallization assays containing agarose gel were stored at $20^{\circ} \mathrm{C}$.

\subsection{Solubility measurements}

Drops composed of $5 \mu \mathrm{l}$ virus and $5 \mu \mathrm{l}$ crystallant solution were deposited on $22 \mathrm{~mm}$ round glass coverslips treated to be waterrepellent and placed over $500 \mu \mathrm{L}$ reservoirs in Linbro plates. Assays were left undisturbed for 3 months at $20^{\circ} \mathrm{C}$ to reach the equilibrium by vapor diffusion. After this time, two independent measurements were performed. For each, a $1 \mu \mathrm{l}$ sample was collected under the binocular with a pipette equipped with a thin tip from a part of the drop that contained neither crystals nor precipitate. It was mixed with $5 \mu$ l water before the absorbance was measured at $260 \mathrm{~nm}$. The virus concentration in equilibrium with the crystals is called the solubility $S$. Supersaturation $(\sigma)$ is defined as the quotient of the initial concentration $C$ in the crystallization drop over $S$, such as $\sigma=C / S$ (Riès-Kautt and Ducruix, 1999).

\subsection{X-ray analysis}

Prior to flash cooling in a nitrogen stream, crystals were transferred for $15 \mathrm{~s}$ in a cryo-protectant solution composed of $100 \mathrm{mM}$ Hepes, pH 7.2, 30\% (v/v) glycerol, and 1\% (m/v) PEG-3350 in excess to the concentration in the crystallization drop. Crystals grown in gel contain the polymer in their solvent channels (Gavira and Garcia-Ruiz, 2002). They were carefully dissected using microtools (e.g. thin steels needles) and subsequently treated as crystals grown in solution. A pyramidal crystal of the GFLV-TD variant measuring $250 \mu \mathrm{m}$ across was analyzed on the FIP-BM30 beamline at the European Synchrotron Radiation Facility (Grenoble, France) using an ADSC Q315r detector (wavelength $0.98 \AA$, crystal-todetector distance $500 \mathrm{~mm}$ ). A first set of 121 images (oscillation angle $0.25^{\circ}$, exposure $120 \mathrm{~s}$ ) was merged with a second one (oscillation angle $0.2^{\circ}$, exposure $120 \mathrm{~s}$ ). The latter set initially encompassed 1100 images, but frames recorded beyond number 400 were discarded because of significant radiation damage (Table 1). Crystals of both virus types were also irradiated on Beamline X06DA of the Swiss Light Source at the Paul Scherrer Institute (Villigen, Switzerland). Sets of 400 or 600 diffraction images (exposure $2 \mathrm{~s}$, oscillation angle $0.3^{\circ}$ ) were collected (Table 1 ). Data were processed with XDS and XSCALE (Kabsch, 2001). Indexed intensities were converted to structure factors without any sigma cut-off using TRUNCATE and non-crystallographic symmetry elements associated to the viral capsid were searched in the Self-rotation function using POLARRFN, two programs from the CCP4 package (Collaborative Computational Project Number 4, 1994).

\section{Results}

\subsection{Quality control of GFLV preparations}

The small amount of virus recovered from the host plants ( $1 \mathrm{mg} / \mathrm{kg}$ leaves) was not a major obstacle but it was essential to determine precisely and reproducibly the virus concentration in the samples used for crystallization assays. The purification protocol of GFLV yields a mixture of capsids containing nucleic acids of various lengths and of empty capsid shells. Three distinct populations (called Top, Middle and Bottom components) can be separated in a density gradient. All these virions have the same size and shape but they differ by their UV absorbance properties (Mayo and Robinson, 1996). A 1/1/1 mixture of the three types of capsids has an extinction coefficient $E_{260 \mathrm{~nm}}$ of $9.0 \mathrm{mg} / \mathrm{ml} / \mathrm{cm}$ calculated on the basis of its amino acid and nucleotide composition. To estimate the $E_{260 n m}$ of GFLV, we compared the intensity of light scattered by a solution of known absorbance to that of a solution at a known concentration of Brome mosaic virus (BMV) whose particles have the same diameter but an $\mathrm{E}_{260 \mathrm{~nm}}$ of $5.0 \mathrm{mg} / \mathrm{ml} / \mathrm{cm}$ (Lorber et al.,

Table 1

X-ray analysis of GFLV crystals.

\begin{tabular}{|c|c|c|c|c|}
\hline Virus & GFLV-F13 & GFLV-F13 & GFLV-F13 & GFLV-TD \\
\hline Crystallization medium at $293 \mathrm{~K}$ & Solution & Gel & Gel & Solution \\
\hline \multicolumn{5}{|l|}{ Data collection at $100 \mathrm{~K}$} \\
\hline Beamline & SLS/X06DA & SLS/X06DA & SLS/X06DA & ESRF/BM30 \\
\hline Detector & Mar CCD 225 & Mar CCD 225 & Mar CCD 225 & ADSC Q315r \\
\hline Wavelength $(\AA)$ & 1.00 & 0.979 & 0.979 & 0.980 \\
\hline Oscillation $\left({ }^{\circ}\right)$ & 0.3 & 0.3 & 0.3 & $0.25 / 0.2$ \\
\hline Number of frames & 600 & 600 & 400 & $121 / 400$ \\
\hline \multicolumn{5}{|l|}{ Statistics } \\
\hline Space group (number) & P1 (1) & P1 (1) & P2 (3) & $\mathrm{P} 2{ }_{1} 3(198)$ \\
\hline \multirow[t]{3}{*}{ Unit cell lengths a, b, c $(\AA)$} & 278.4 & 279.4 & 283.8 & 408.0 \\
\hline & 298.3 & 279.5 & 295.5 & 408.0 \\
\hline & 291.6 & 293.3 & 393.7 & 408.0 \\
\hline \multirow[t]{3}{*}{ Unit cell angles $\alpha, \beta, \gamma\left(^{\circ}\right)$} & 102.0 & 102.4 & 90.0 & 90.0 \\
\hline & 116.4 & 116.4 & 91.5 & 90.0 \\
\hline & 108.2 & 108.2 & 90.0 & 90.0 \\
\hline Crystal mosaicity $\left(^{\circ}\right)$ & 0.08 & 0.10 & 0.15 & 0.07 \\
\hline Resolution range $(\AA)$ & $100-5.5$ & $135-3.0$ & $100-3.7$ & $36-2.7$ \\
\hline Highest resolution shell ( $\AA$ ) & $5.64-5.5$ & $3.08-3.0$ & $3.8-3.7$ & $2.77-2.7$ \\
\hline No. of observations & 394916 & 2416076 & 1710375 & 6205218 \\
\hline No. of unique reflections & $198238(13886)$ & $1214336(73170)$ & $572178(19142)$ & $563202(32448)$ \\
\hline Completeness (\%) & $88.8(84.1)$ & $88.1(71.7)$ & $83.1(76.5)$ & $92.0(72.0)$ \\
\hline Multiplicity & $2.0(2.0)$ & $2.0(1.9)$ & $3.0(3.0)$ & $11.0(3.1)$ \\
\hline$R_{\text {merge }}(\%)^{\mathrm{a}}$ & $13.9(25.5)$ & $10.0(35.0)$ & $18.8(49.5)$ & $12.5(68.1)$ \\
\hline$<I / \sigma(I)>$ & $7.2(3.4)$ & $9.2(2.4)$ & $7.3(2.5)$ & $18(1.9)$ \\
\hline Asymmetric unit content & 60 -mer & 60-mer & 60-mer & 20-mer \\
\hline Matthews coefficient $\left(\AA^{3} \mathrm{Da}^{-1}\right)$ & 5.2 & 5.2 & 4.8 & 5.0 \\
\hline Protein content (\%) & 26 & 26 & 24 & 25 \\
\hline
\end{tabular}

Statistics are given for reflections with $I \geqslant 0$ and values in parentheses are for the highest resolution shell.

${ }^{\text {a }} R_{\text {merge }}=\sum_{h k l} \Sigma_{i}\left|I_{i}(h k l)-<I(h k l)>\right| / \sum_{h k l} \Sigma_{i} I_{i}(h k l)$. 

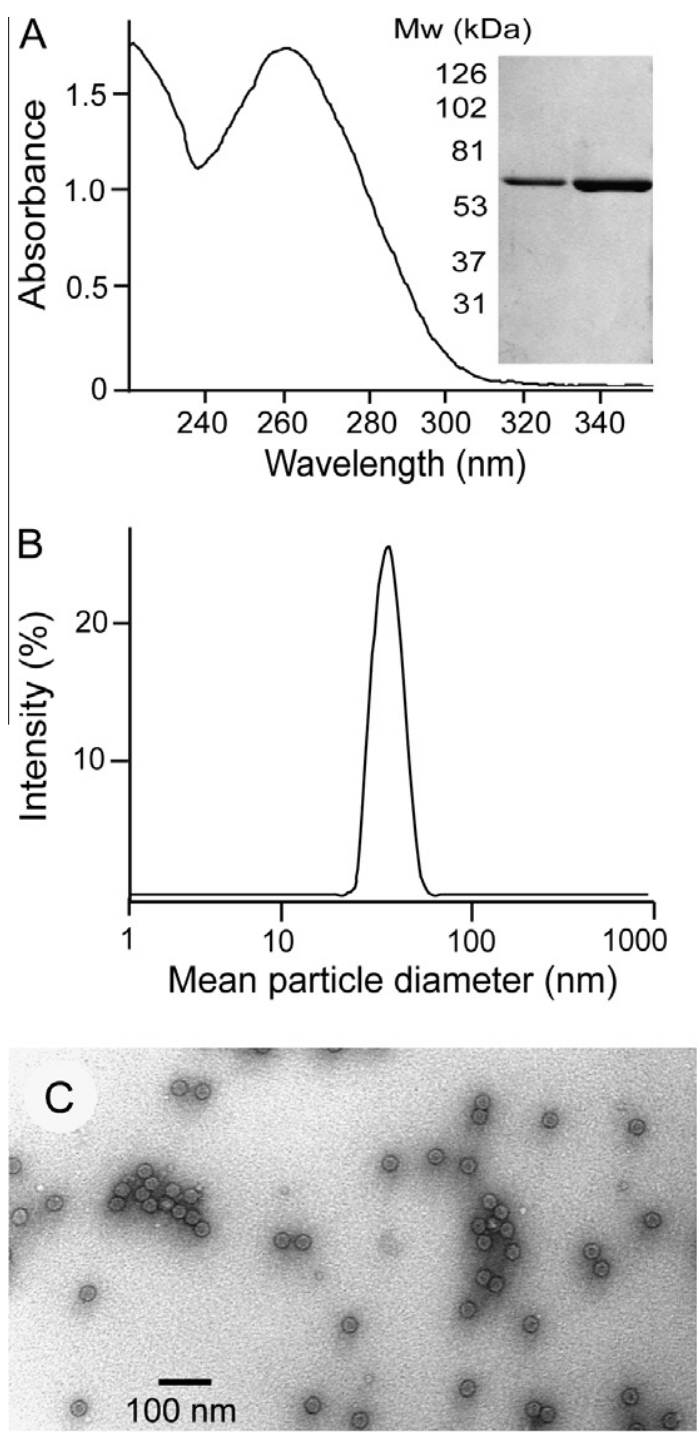

Fig.1. Purity and homogeneity of GFLV preparations. GFLV-F13 and its variant GFLV-TD gave comparable results. (A) UV-absorbance spectrum and (inset) Coomassie blue staining after SDS-PAGE separation. Lane 1 and 2 correspond to 5 and $10 \mu \mathrm{g}$ protein, respectively. (B) Intensity particle size distribution from dynamic light scattering analysis of virus in $0.15 \mathrm{M} \mathrm{NaCl}$. Mean particle diameter is $31 \pm 2 \mathrm{~nm}$ and polydispersity about $5 \%$. (C) Electron micrograph of virions after negative staining.

2008). The value determined experimentally was the same as the one above.

Second, the purified viral particles destined to crystallization assays had to be free of contaminants and homogeneous in size and shape. For this reason, we systematically performed a full set of analyses on every GFLV preparation. Electrophoresis, light scattering and electron microscopy were routine diagnostic tools to select the best virus batches for crystallization. Our purification protocol yielded virions that were pure according to their UV absorbance properties $\left(1.80<\mathrm{A}_{260 \mathrm{~nm}} / \mathrm{A}_{280 \mathrm{~nm}}<1.97\right)$. The electrophoretic mobility pattern of the capsid protein did not reveal any co-purified polypeptide chain (Fig. 1A). A single chain with a molecular weight of $\sim 56 \mathrm{kDa}$, as expected from amino acid composition, was found when the content of pure preparations was separated under denaturing conditions (Serghini et al., 1990). Dynamic light scattering analyses indicated that the hydrated virions have a mean diameter of $31 \pm 2 \mathrm{~nm}$ with a polydispersity of $\leqslant 5 \%$ (Fig. 1B). Sometimes minor batch-to-batch variations were detected by this non-invasive method. Transmission electron microscopy (TEM) analyses of the most pure samples showed that they were composed of a majority of filled quasi-spherical capsids accompanied by a few empty ones, all with a diameter of 29$30 \mathrm{~nm}$ after dehydration (Fig. 1C). Careful inspection of the micrographs revealed in some batches the presence of a number of small-size particles that could be protein aggregates. These less pure samples yielded small ill-shaped crystals or precipitates and were not useful for structure determination.

\subsection{Identification of the most promising crystal form}

Crystallization conditions for GFLV-F13 and GFLV-TD were searched using a commercial sparse matrice composed of 96 crystallant solutions. After 4 -weeks equilibration by vapor diffusion at $20^{\circ} \mathrm{C}$ several drops produced crystals of various habits that were not birefringent in polarized light (Fig. 2). Two polyethylene glycol solutions gave most hits. The first contained PEG-1500 with or without sodium phosphate buffer, $\mathrm{pH} 7.2$ and the second PEG3350 and $0.1 \mathrm{M}$ Hepes, pH 7.5 with or without $0.2 \mathrm{M}$ proline. Our subsequent assays explored broader ranges of virus and PEG concentrations. In some cases only a single crystal was obtained with dimensions exceeding $100 \mu \mathrm{m}$ across. In others the crystals were not stable at all or could not be reproduced. Irradiation with a laboratory rotating anode was used to identify the crystal form yielding the most rich diffraction pattern. It was then necessary to augment crystal volume and diffraction power.

\subsection{Crystal growth improvement using phase diagrams}

At the very beginning, the GFLV-TD crystals found in a drop containing 10\% (m/v) PEG-3350, $0.2 \mathrm{M}$ proline and 0.1 M Hepes, $\mathrm{pH} 7.5$, had an ill-defined polyhedral habit and dimensions below $30 \mu \mathrm{m}$. They were accompanied by numerous dendrites and spherulites (result not shown) growing at very high supersaturation and known to be unsuitable for high-resolution diffraction analyses (Sunagawa, 2005). At lower virus and crystallant concentrations the rate of nucleation was reduced, dendrites and precipitate were eliminated, and the growth of large crystals was
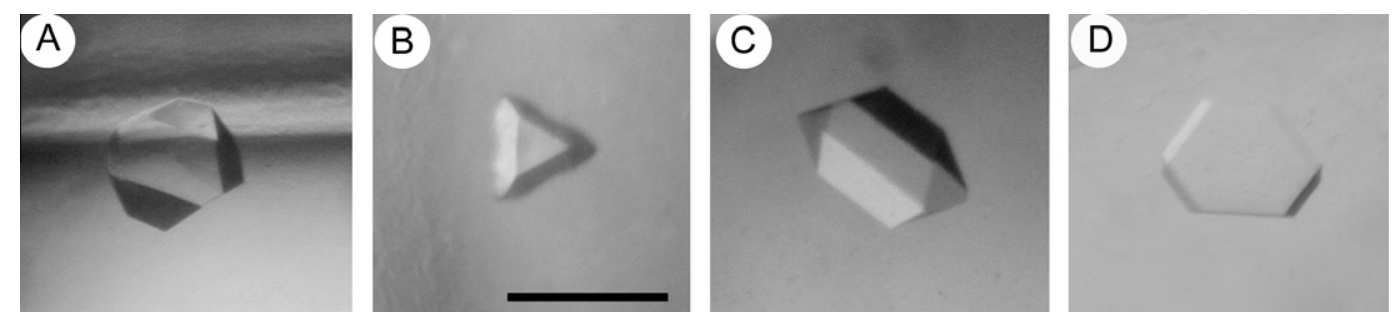

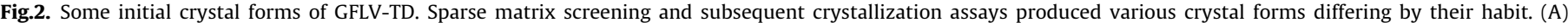

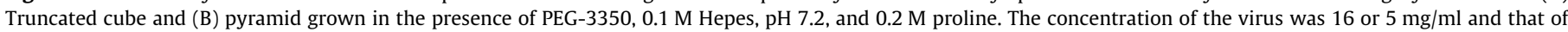



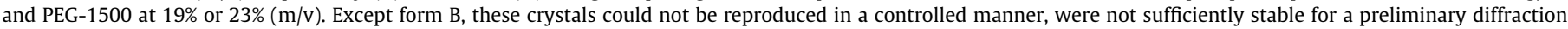
analysis or did not diffract X-rays at all. Scale bar is $200 \mu \mathrm{m}$. 
promoted. To delimit the conditions producing the latter, sets of 16 drops in squares covering 4 virus and 4 PEG concentrations were prepared manually. Further, drop volume was tripled to make a greater amount of virus available for crystal growth. A typical example of the consequence of the reduction of virus concentration is displayed Fig. 3. As shown in panel B, there were fewer dendrites, no precipitate, and the pyramidal habit of the crystals could be recognized. After a second round of condition refinement at lower PEG concentration, the drops contained just a few single crystals measuring up to $150 \mu \mathrm{m}$ across and a few large dendrites (Fig. 3B). Finally, after minor adjustments single crystals with a diameter of up to $300 \mu \mathrm{m}$ were obtained in a solution containing $4 \mathrm{mg} / \mathrm{ml} \mathrm{GFLV-TD} \mathrm{and} \mathrm{7 \%} \mathrm{(m/v)} \mathrm{PEG-3350} \mathrm{(Fig.} \mathrm{3C).}$

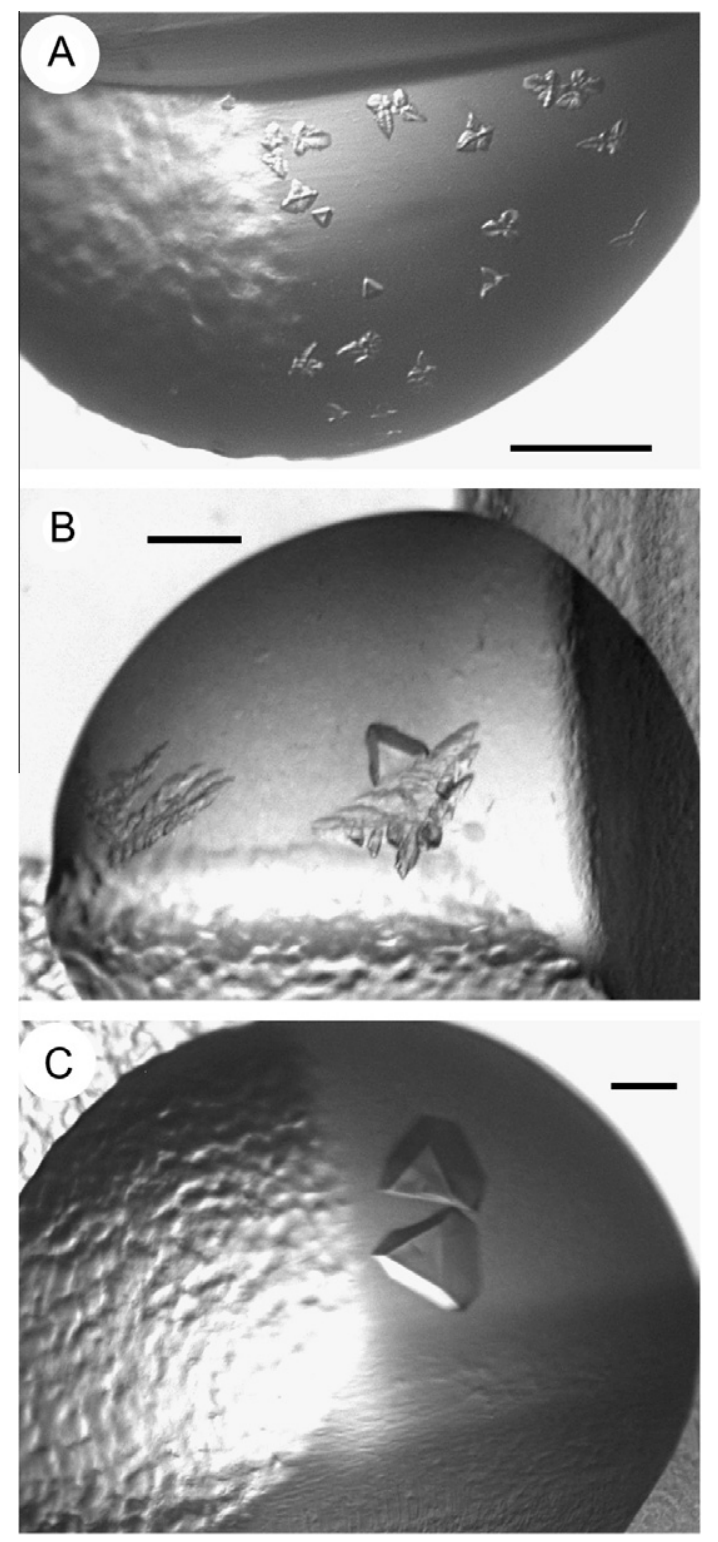

Fig.3. Optimization of GFLV-TD crystallization. (A) Assay containing GFLV-TD at $6.5 \mathrm{mg} / \mathrm{ml}$ and $10 \%(\mathrm{~m} / \mathrm{v})$ PEG-3350. After 7 days, crystallization yields many dendrites and a few truncated pyramidal crystals. (B) Single crystal accompanied by a few dendrites obtained after 7 days at $5 \mathrm{mg} / \mathrm{ml}$ virus and $8 \%(\mathrm{~m} / \mathrm{v})$ PEG (same condition as in Panel B of Fig. 2). (C) Large crystals in clear solution at $4 \mathrm{mg} / \mathrm{ml}$ virus and $7 \%(\mathrm{~m} / \mathrm{v})$ on day 10 . In all pictures the drop volume is $1 \mu \mathrm{L}$ and the scale bar corresponds to $200 \mu \mathrm{m}$. A similar optimization protocol was applied to the wild type strain GFLV-F13.
The best condition found for GFLV-TD turned out to be ineffective with GFLV-F13: it gave numerous tiny crystals and dendrites (result not shown). For this reason we applied the same approach as the one implemented with GFLV-TD to grow large single crystals with well-developed facets. Best crystals were truncated monoclinic prisms (not shown). They reached $200 \mu \mathrm{m}$ in length and grew at virus and PEG concentrations of $1.8-2.2 \mathrm{mg} / \mathrm{ml}$ and $3.0-$ $4.0 \% \mathrm{~m} / \mathrm{v}$, respectively. Interestingly, these concentrations were approximately half of those required to produce best GFLV-TD crystals. Arrows in Fig. 4 indicate the paths followed during the optimization of the crystal growth of each virus, from initial crystals ( $\mathrm{I}$ and $\mathrm{I}^{\prime}$ ) to optimized crystals $\left(\mathrm{C}\right.$ and $\left.\mathrm{C}^{\prime}\right)$. Hatched curves symbolize the hypothetical solubility lines separating the regions where the viruses do crystallize from those below where they do not. Experimental solubilities (plotted as open and closed circles) were $1.3 \pm 0.3 \mathrm{mg} / \mathrm{ml}$ and $3.3 \pm 0.5 \mathrm{mg} / \mathrm{ml}$ in the presence of $7 \%$ $(\mathrm{m} / \mathrm{v})$ PEG-3350 for GFLV-F13 and GFLV-TD, respectively.

\subsection{Crystal quality enhancement by growth in agarose gel}

Crystals of GFLV-F13 and GFLV-TD were analyzed on synchrotron X-ray sources. The diffraction limit of those of GFLV-TD grown in solution ranged from 3.5 to $4.5 \AA$ on average and one sample exhibited well-resolved diffraction patterns with reflections beyond $3 \AA$ (Fig. $5 A$ ). In contrast, most GFLV-F13 crystals did not diffract $X$-rays to a resolution better than $6 \AA$. The absence of ice rings suggested that cryoprotection was sufficient but only one crystal out of two dozen had a diffraction limit of $5.5 \AA$ at best (Fig. 5B). No enhancement was noticed by varying neither the composition of crystallization and cryoprotectant solutions nor the crystal soaking duration before flash cooling. Knowing that virus crystals may be more sensitive to handling than most protein crystals and that crystallization in gel can help circumvent this limitation, we decided to add $0.2 \%(\mathrm{~m} / \mathrm{v})$ agarose to the crystallization assays of GFLV-F13. Another reason to crystallize in the presence of gel was that the mesh of the polymer network immobilizes the crystal

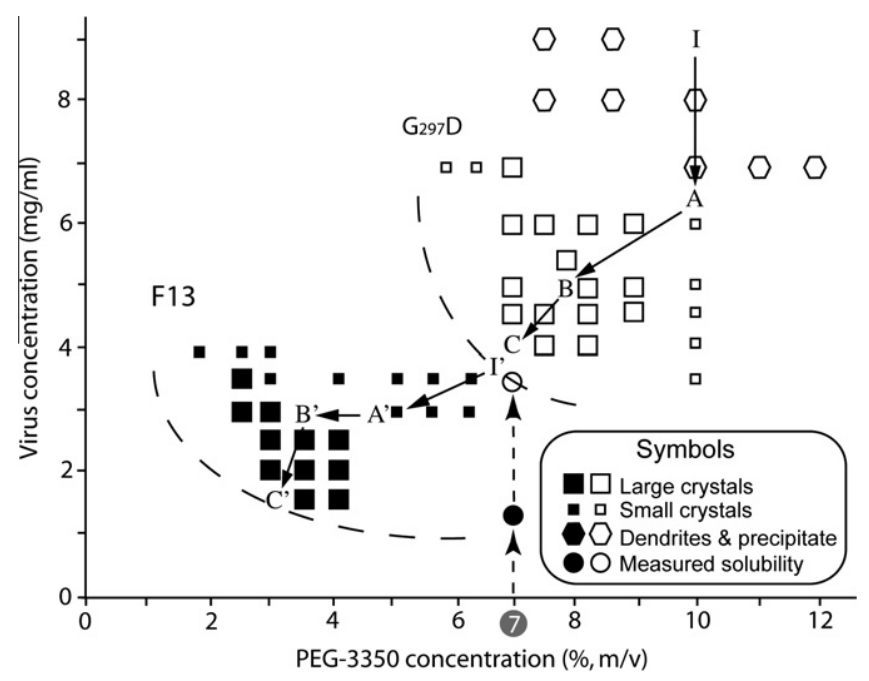

Fig.4. Superimposed phase diagrams of GFLV-F13 and GFLV-TD. Both diagrams were obtained from independent crystallization assays done at $20^{\circ} \mathrm{C}$ in $1 \mu \mathrm{L}$ sitting drops. They are superimposed to facilitate comparison. Symbols stand for the major crystal form observed through a binocular microscope at a 50 -fold magnification. Solid symbols represent data from GFLV-F13 and open symbols those of GFLV-TD. The composition of the drop in the initial screen done on GFLV-TD (I) and that of drops A, B and C in Fig. 3 is indicated. The path followed during the optimization of GFLV-F13 crystals is indicated by the letters $\mathrm{I}^{\prime}, \mathrm{A}^{\prime}, \mathrm{B}^{\prime}$, and $\mathrm{C}^{\prime}$. Experimental solubilities (1.3 and $3.3 \mathrm{mg} / \mathrm{ml}$ for GFLV-F13 and GFLV-TD, respectively), are given by round symbols. For each variant, no crystals was observed in samples having compositions located below the respective dashed solubility curve. 


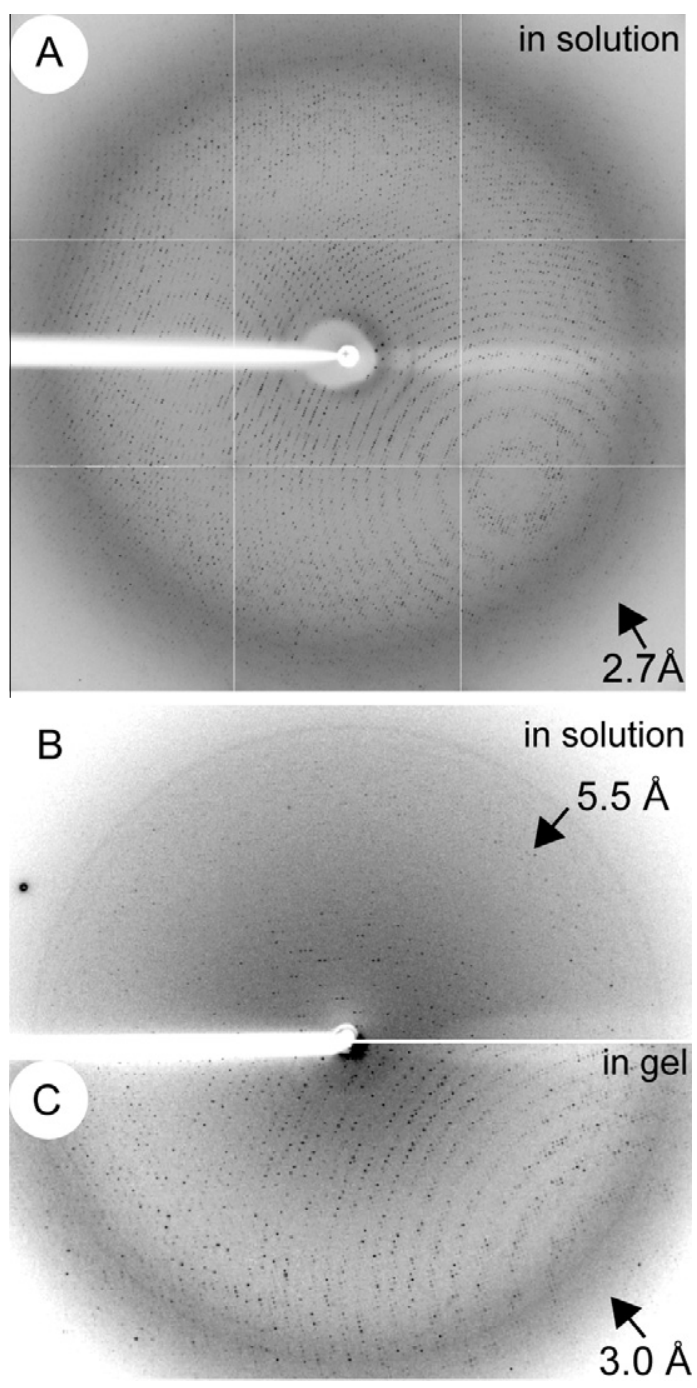

Fig.5. Diffraction limits of GFLV-F13 and GFLV-TD crystals at $100 \mathrm{~K}$. From top to bottom: Diffraction patterns of best crystals of GFLV-TD grown in solution (A) and of GFLV-F13 grown in solution (B) or in gel (C). Arrows indicate the diffraction limits of 5.5, 3.0, and $2.7 \AA$ A, respectively. See Table 1 for details.

nuclei and favors their growth in three dimensions. Hence, it protects the crystalline lattice against mechanical shocks during crystal transport and harvesting and against thermal shocks during cryocooling. As a consequence, the diffraction properties may be enhanced (Lorber et al., 2009). Here, the presence of the gel extended the diffraction limit of the GFLV-F13 crystals to $3 \AA$ (Fig. 5C). Overall, gel-grown crystals proved to be less fragile and displayed an improvement in net resolution of 2-3 $\AA$ compared to those produced in the absence of agarose.

\subsection{Preliminary crystallographic analyses}

Table 1 summarizes the results of preliminary crystallographic analyses of solution and gel-grown GFLV crystals. Two crystal forms of GFLV-F13 were characterized; a triclinic one (grown and analyzed in solution or in gel) and a monoclinic one (grown and analyzed in gel). The crystal form of GFLV-TD was cubic. Alike many virus crystals, those of GFLV exhibited a low mosaicity $\left(0.07-0.15^{\circ}\right)$ even though they were analyzed at cryogenic temperatures. A decrease of the high resolution signal in the 3-4 Å resolution range occurred after collecting 500-600 images. This corresponds to an absorbed dose of 13-16 MGy on either beamline as calculated with RADDOSE (Paithankar and Garman, 2010). Data collection strategies were adjusted accordingly to maximize data completeness and to limit the effect of radiation damage. As a consequence, a completeness of $100 \%$ could not be achieved for low symmetry (i.e. P1 and P2) crystal forms. However, this is not expected to be detrimental for structure determination because of the high non-crystallographic redundancy of the capsids which is made of 60 identical protein subunits. Indeed, the icosahedral 532 point group symmetry was clearly detected for each of the three crystal forms. In the cubic ones, the viral 3-fold axis coincided with the crystallographic 3 -fold axis (not shown). The most probable content of the respective asymmetric units is one third of a capsid (or 4 pentamers) in cubic crystals and a complete capsid in both GFLV-F13 crystal forms. This corresponds to a protein content of about $25 \%$ in volume in the three cases. For the evolutionary-related TRSV whose crystals have a similar protein content ( $\sim 23 \%$ ), the solvent surrounding the virions occupies $32 \%$ of the unit cell volume, considering that the genomic RNA fills the interior of the capsid and the mean outer radius of the particle is $140 \AA$. This means that the virions are rather densely packed inside the crystals. Interestingly, cubic GFLV crystals and TRSV crystals have in common two unit cell dimensions and the same crystal density. This supports the idea that both viruses are very similar in shape and that TRSV (PDB Accession Code 1A6C) (Chandrasekar and Johnson, 1998) is a good starting model for molecular replacement.

\section{Discussion}

Many biocrystallography projects fail because of the impossibility to grow suitable crystals or to reproduce positive hits. In the case of GFLV-F13 and of its variant GFLV-TD several implementations helped grow and reproduce the crystals and make them diffract at high resolution. As soon as a promising crystallant was identified, two-dimensional phase diagrams covering a range of virus and crystallant concentrations were used to find optimal growth conditions. Also, the stability of GFLV-F13 crystals during the flash cooling procedure was enhanced and their diffraction limit extended by growing them in the presence of a low concentration of agarose gel.

\subsection{Importance of virus purity and homogeneity}

Crystal defects may be generated by contaminants competing with virions during crystal growth. Indeed, virus crystals can incorporate without discrimination a wide panel of impurities, from small molecules to larger viruses (Kuznetsov et al., 2005). The disadvantage of most virus purification protocols is that they cannot separate particles with very little differences in shape, charge, size or eliminate proteins possessing some affinity with the virus. For example, an $\alpha$-glucosidase from the host plant interacts strongly and co-purified with the polerovirus Beet western yellows virus (Schellenbaum et al., 2003). Further, seasonal variations in the host plant's physiological state can change sample composition and levels of contaminants in virus preparations. Quacquarelli et al. (1976) found that the relative proportions of $\mathrm{T}, \mathrm{M}$. and $\mathrm{B}$ components of GFLV purified from $C$. quinoa plants varied from 1/0.5/3.5 in summer to $1 / 0.5 / 0.75$ in winter. We applied rigorously the same purification protocol to the plant material and noticed that the homogeneity of the virus sample (analyzed by DLS) and the amount of protein contaminants (detected as an excess of UV absorbance and visible in the electron microscope) varied over the year. In the absence of further investigations we preferred to use only the less contaminated samples for crystallization. The fact that we worked exclusively with the purest and most 
homogeneous virus batches of both variants ensured the reproducibility of the crystallization results.

\subsection{Advantage of phase diagrams and determination of virus solubility}

The visual inspection of the result of a small number of individual crystallization assays was sufficient to get a gross idea of the location of the unsaturated region (where the solution remains clear and no crystal grows), the supersaturated region (where either crystals or precipitate form), and the solubility curve separating them (Fig. 3). In the case of GFLV, minor variations in virus and/or crystallant concentration led to significant changes in the crystallization outcome. Therefore, it was crucial to delineate the exact composition of the solution favoring the best crystallization.

We noticed also that both variants did not behave in the same way with regard to their solubility. Indeed, the single mutation from Gly to Asp dramatically altered the crystallization phase diagram of GFLV in a given crystallant. The knowledge of the two phase diagrams and of a few experimental solubility data permitted to correlate the addition of a carboxyl group to a 2.5-fold increase in virion solubility. This result suggested that this residue is accessible to the solvent, as predicted by the superimposition of GFLV capsid protein sequence onto TRSV crystal structure (Chandrasekar and Johnson, 1998). The more soluble virions crystallized more easily presumably because supersaturation varied more slowly during drop equilibration when the composition of the drops crosses the nucleation zone (Sauter et al., 2011). Cubic symmetry was another parameter which may have favored packing regularity. In contrast, the less soluble variant crystallization was more sensitive to supersaturation variations. In such a situation, slightly too high supersaturation rapidly led to fast and uncontrolled nucleation, to changes in growth mechanism accompanied by the incorporation of lattice defects, and ultimately to reduced diffraction properties.

Interestingly, the degree of supersaturation $(\sigma)$ that is required to trigger nucleation and to sustain the growth of GFLV-F13 and GFLV-TD crystals with best geometry and greatest dimensions did not exceed 2. This is comparable to the supersaturation $(2<\sigma<3)$ at which Tomato bushy stunt virus crystallizes at low PEG-8000 or ammonium sulfate concentration (Lorber and Witz, 2008). Similarly, phase diagram studies showed that BMV crystals can grow near the solubility curve, i.e. at $1.5 \leqslant \sigma \leqslant 2$ in the presence of PEG-8000 or PEG-20000 (Casselyn et al., 2001). GFLV is composed of 60 equivalent capsid proteins which have a defined position and orientation in the icosahedral assembly. Hence, a virion has 60 times more possibilities than an asymmetrical macromolecule to bind readily in the right orientation at the surface of a growing crystal. Further, the fact that at equal molar concentration the virus occupies a much greater volume in solution than individual protein molecules makes nucleation possible at much lower concentrations (Lorber and Witz, 2008). Altogether, this explains why at extremely low supersaturation enough driving force is available to nucleate and grow virus crystals. The lowest levels are still much higher than the supersaturation required to crystallize small molecules like salts (Boistelle and Astier, 1988).

\subsection{Advantage of crystallization in agarose}

Crystals of wild-type GFLV-F13 diffracting to high resolution were obtained by adding agarose gel. The positive effect of the gel was already observed with various proteins (Lorber et al., 2009) and was due to the fact that a polysaccharide network is entrapped inside the channels of the crystals during growth. Consequently, it stabilized the lattice (Gavira and Garcia-Ruiz, 2002). The fibers of the gel reinforced the crystals and prevented the decay or loss of diffraction properties upon cryocooling (Zhu et al.,
2001; Biertumpfel et al., 2005). Moreover, it provided a convection-free environment suitable for the slow growth of well-ordered crystals.

\subsection{Perspectives}

The strategies implemented for GFLV can be applied to other quasi-spherical viruses and some of them to any biological macromolecules. On the one hand phase diagrams can be useful to define reproducible crystallization conditions at low supersaturation producing single crystals with large volumes and best diffraction properties. On the other hand, gels reinforce crystalline lattices and stabilize them before the thermal shock of cryocooling preceding diffraction analyses. Finally, this study confirms that icosahedral viruses crystallize at lower PEG concentrations and that conventional screens should be adapted accordingly.

\section{Acknowledgments}

The authors thank the European Synchrotron Radiation Facility and the Swiss Light Source for the beamtime allocated to this project. In particular, they acknowledge the help of M. Pirrochi and J.L Ferrer (on beamline FIP-BM30 at ESRF) and of M. Wang (on beamline X06DA at SLS). They are grateful to C. Schulze-Briese and F. Rey for interest in this project. They acknowledge R. Giegé and M. RièsKautt for stimulating discussions and the staff of the Experimental Unit at INRA Colmar for rearing the plants. P. Schellenberger was supported by a fellowship from Département Santé des Plantes et Environnement (SPE-INRA) and the Conseil Interprofessionnel des Vins d'Alsace (CIVA). This work was supported by grants from the Département Santé des Plantes et Environnement (SPE-INRA), CNRS and the Université de Strasbourg.

\section{References}

Andret-Link, P., Laporte, C., Valat, L., Ritzenthaler, C., Demangeat, G., Vigne, E., Laval, V., Pfeiffer, P., Stussi-Garaud, C., Fuchs, M., 2004. Grapevine fanleaf virus: Still a major threat to the grapevine industry. J. Plant Pathol. 86, 183-195.

Biertumpfel, C., Basquin, J., Birkenbihl, R.P., Suck, D., Sauter, C., 2005. Characterization of crystals of the Hjc resolvase from Archaeoglobus fulgidus grown in gel by counter-diffusion. Acta Cryst. F61, 684-687.

Boistelle, R., Astier, J.P., 1988. Crystallization mechanisms in solution. J. Cryst. Growth 90, 14-30.

Casselyn, M., Perez, J., Tardieu, A., Vachette, P., Witz, J., Delacroix, H., 2001. Spherical plant viruses: Interactions in solution, phase diagrams and crystallization of brome mosaic virus. Acta Cryst. D57, 1799-1812.

Chandrasekar, V., Johnson, J.E., 1998. The structure of tobacco ringspot virus: a link in the evolution of icosahedral capsids in the picornavirus superfamily. Structure 6, 157-171.

Collaborative Computational Project Number 4, 1994. Acta Cryst. D50, 760-763.

Ducruix, A., Giegé, R., 1999. Crystallization of Nucleic Acids and Proteins: A Practical Approach. IRL press, Oxford University Press.

Gan, L., Johnson, J.E., 2008. An optimal exposure strategy for cryoprotected virus crystals with lattice constants greater than 1000 Å. J. Synchrotron Radiat. 15, 223-226.

Gavira, J.A., Garcia-Ruiz, J.M., 2002. Agarose as crystallisation media for protein: trapping of gel fibers into the crystals. Acta Cryst. D58, 1653-1656.

Girard, E., Kahn, R., Mezouar, M., Dhaussy, A.C., Lin, T., Johnson, J.E., Fourme, R., 2005. The first crystal structure of a macromolecular assembly under high pressure: cpmv at 330 MPa. Biophys. J. 88, 3562-3571.

Kabsch, W., 2001. In: Rossmann, M.G., Arnold, E. (Eds.), XDS in Crystallography of Biological Macromolecules. Kluwer Academic Publishers.

Kuznetsov, Y.G., Makino, D.L., Malkin, A.J., McPherson, A., 2005. The incorporation of large impurities into virus crystals. Acta Cryst. D61, 720-723.

Lorber, B., Adrian, M., Witz, J., Erhardt, M., Harris, J.R., 2008. Formation of twodimensional crystals of icosahedral RNA viruses. Micron 39, 431-446.

Lorber, B., Witz, J., 2008. An investigation of the crystallogenesis of an icosahedral RNA plant virus with solubility phase diagrams. Cryst. Growth Des. 8, 15221529.

Lorber, B., Sauter, C., Theobald-Dietrich, A., Moreno, A., Schellenberger, P., Robert, M.-C., Capelle, B., Sanglier, S., Potier, N., Giegé, R., 2009. Crystal growth of proteins, nucleic acids, and viruses in gels. Prog. Biophys. Mol. Biol. 101, 13-25.

Mayo, M.A., Robinson, D.G., 1996. Nepoviruses: molecular biology and replication In: Harrison, B.D., Murrant, A.F. (Eds.), The Plant Viruses, Polyhedral Virions and Bipartite RNA Genomes. Plenum Press, pp. 287-288. 
McPherson, A. (1999). Crystallization of biological macromolecules, Cold spring Harbor Laboratory Press.

Paithankar, K.S., Garman, E.F., 2010. Know your dose. Acta Cryst. D 66, 381-388.

Pinck, L., Fuchs, M., Pinck, M., Ravelonandro, M., Walter, B., 1988. A satellite RNA in Grapevine fanleaf virus Strain F13. J. Gen. Virol. 69, 233-239.

Pinck, M., Reinbolt, J., Loudes, A.M., Le Ret, M., Pinck, L., 1991. Primary structure and location of the genome-linked protein $(\mathrm{VPg})$ of grapevine fanleaf nepovirus. FEBS Lett. 284, 117-119.

Quacquarelli, A., Gallitelli, V., Savino, V., Martelli, G.P., 1976. Properties of Grapevine fanleaf virus. J. Gen. Virol. 32, 349-360.

Riès-Kautt, M., Ducruix, A., 1999. In: Ducruix, A., Giegé, R. (Eds.), Crystallization of nucleic acids and proteins: a practical approach. IRL Press, Oxford University Press, pp. 269-312.

Sanfaçon, H., 2008. Nepoviruses. in: Mahy, B.W.J., Van Regenmortel, M.H.V. (Eds.) Encyclopedia of Virology, pp. 405-413.

Sauter, C., Dhouib, K., Lorber, B., 2007. From macrofludics to microfluidics or the crystallization of biological macromolecules. Cryst. Growth Des. 7, 2247-2250.

Sauter, C., Lorber, B., McPherson, A., Giegé, R., 2011. Crystallization - Genera methods in International Table for Macromolecular Crystallography, in: M. Rossman, M., Arnold E. (Eds.), International Table for Macromolecular Crystallography, International Union of Crystallography, in press.
Schellenbaum, P., Minic, Z., Beuve, M., Herrbach, E., Jouanin, L., Reinbold, J., Vantard, M., Lemaire, O., 2003. in: Advances in Plant Virology, colloque AAB, Montpellier. Schellenberger, P., Andret-Link, P., Schmitt-Keichinger, C., Bergdoll, M., Marmonier, A., Vigne, E., Lemaire, O., Fuchs, M., Demangeat, G., Ritzenthaler, C., 2010. A stretch of 11 amino acids in the B-C loop of the coat protein of Grapevine fanleaf virus is essential for transmission by the nematode Xiphinema index. J. Virol. 84, 7924-7933.

Serghini, M.A., Fuchs, M., Pinck, M., Reinbolt, J., Walter, B., Pinck, L., 1990. RNA2 of grapevine fanleaf virus: sequence analysis and coat protein cistron location. J. Gen. Virol. 71, 1433-1441.

Sunagawa, I., 2005. Crystals, Growth, Morphology, and Perfection. Cambridge University Press, Cambridge, UK.

Viry, M., Serghini, M.A., Hans, F., Ritzenthaler, C., Pinck, M., Pinck, L., 1993. Biologically active transcripts from cloned cDNA of genomic grapevine fanleaf nepovirus RNAs. J. Gen. Virol. 74, 169-174.

Vuittenez, M., Munck, M.C., Kuszala, J., 1964. Souches de virus à haute aggressivité isolées de vignes atteintes de dégenerescence infectieuse. Etudes Virol. Appliquée 5, 69-78.

Zhu, D.W., Lorber, B., Sauter, C., Ng, J.D., Benas, P., Le Grimellec, C., Giegé, R., 2001. Growth kinetics, diffraction properties and effect of agarose on the stability of a novel crystal form of Thermus thermophilus aspartyl-tRNA synthetase-1. Acta Cryst. D57, 552-558. 